\title{
Life long learning in a world of globalized knowledge
}

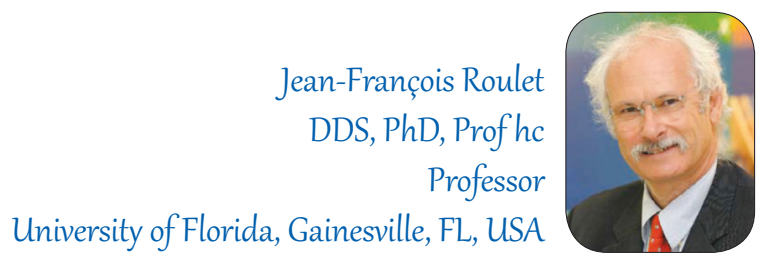

Dear Readers,

We live in a world that is dramatically different from the world 1 was born into more than 65 years ago. When 1 was a student, my main source of information was textbooks. As a young researcherl learned that journals are the source of the most recent advances in my profession. The library was the location where every project started: search the literature. For information on the daily life we usually relied on the local newspaper. Today everything is different. We not only produce much more information and renew knowledge on a much faster pace, but due to the internet, information becomes globally available usually a short time after it happened. If 1 want to go to the movies, I just consult a local website, where all the movie programs of the week are listed. 1 can even buy the tickets right away and select my favorite seats. At home in Gainesville, Florida 1 watch the Swiss TV news and 1 am informed about a flood that happened a few hours before in the area 1 used to live. If 1 want to know something, a scientific fact or something about a person, 1 just access the internet, log in to a known search engine and within seconds 1 have a multitude of information. So someone should think that life long learning has become very easy and that we are moving to a totally informed society. Unfortunately the contrary is happening. It has become much more difficult to be informed, not only because we are almost drowning in the sea of information, but also because there is a problem related to the validity/ truthfulness of the information. You can see this, if you search a topic you are very familiar with. 1 just tested this again on May 3rd 2016 by looking up "amalgam" on a very well known search engine. The result: 8,700,00o hits in 0.41 seconds - impressive, but how to digest that huge amount of information - impossible. So, as everybody would probably do it, 1 start to look into the first hit: there 1 find quite a neutral description of what amalgam is, however with quite some inaccuracies. Furthermore the concerns of the group of people that believe that amalgam is toxic and dangerous for the patient and the dentist's health are reported without validation. 1 personally know that, based on solid research, these concerns can clearly be reduced to a risk which is much smaller than taking an aspirin against a headache. Two entries down the road 1 find an link offered by a tooth paste producer "Dental Amalgam: A Health Risk". There Amalgam and its toxicity is explained in lay terms quite reasonably, but not without errors. And finally amalgam entry \# 9 is called "Dental Amalgam Mercury Solutions" which is the view of the hard core anti amalgam fraction, naming all the false arguments to make you believe that amalgam is a serious and deadly health risk....

1 could tell exactly the same story about fluoride (20,000,00o hits with much more vigorous and contradictory argumentation; the internet offers automatically as search keywords "fluoride dangers, fluoride conspiracy, fluoride side effects and fluoride in water") or any other topic l consider myself competent about. So how should a consumer know which source to trust? My answer as an editor is clear and loud: "read a peer reviewed scientific journal!"

Andreas Linde, the Editor of the Scandinavian Journal of Dental Research once said: "Nothing is scientifically "shown" or "proven" before it has been published in a scientific journal with a peer review system, so one can critically judge what was done, how it was done and evaluate how solid it is." How is this accomplished? Every peer reviewed journal usually has a 
substantial editorial board, which is a list of experts in the field (e.g. see page 4-5). They consult the journal about the philosophy, the topics to be published, the marketing strategy, the format and more general things about the journal. They also conduct reviews of the manuscripts submitted. But this is not sufficient to accomplish the goal of publishing valid data. First a submitted manuscript is checked by the editorial office for the correct format (structure of manuscript, literature quote etc.), then usually the editor in chief checks if the topic of the manuscript is congruent with the topic of the journal and then usually the manuscript is sent to a section or associate editor, which then reads it and if he/she considers it worth being reviewed sends it to at least 2-3 reviewers for anonymous review. These reviewers are experts in the field and work according to a check list, to make sure that the introduction leads the reader comfortably to the "Objective of the study", that materials and methods are understandable and do not contain methodological errors (e.g. lack of control group, or statistical evaluation), that the results are reported in a readable format, that the discussion and conclusions are correct and limited to the facts reported. Then a manuscript is either accepted or rejected by the editor or most probably sent to the authors for revisions, where the authors must decidedly answer the comments of the reviewers. Then finally the manuscript lands on the desk of the editor in chief, who makes the final decision about to publish or not to publish. But, this is not the end of the story. Usually then a language editor checks the correctness of the text and then the layout of the manuscript is done. Before it goes to printing, with the Stoma EduJ the Editor in Chief has a last look at the paper. Ifyou counted correctly, the manuscript has been seen by at least 9 pairs of eyes (of course with a critical brain attached to) before it ends with the readers. Therefore, Dear Readers, if you want to be accurately informed with valid data, read a PEER RREVIEWED JOURNAL.

https://doi.org/10.25241/stomaeduj.2016.3(1-2).edit.1

Sincrerely yours,

J-F Roulet

Editor-in-Chief 